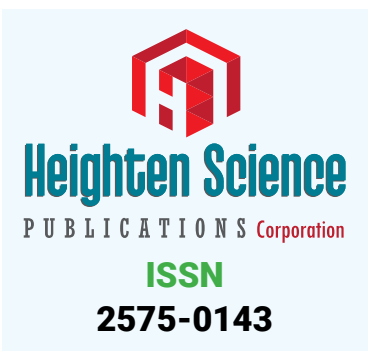

*Address for Correspondence: Felicitas Escher, DZHK (German Centre for Cardiovascular Research), partner site Berlin, Germany, Tel: + 49 30450 665493; Email: felicitas.escher@charite.de

Submitted: 18 June 2019

Approved: 28 June 2019

Published: 01 July 2019

Copyright: () 2019 Escher F, et al. This is an open access article distributed under the Creative Commons Attribution License, which permits unrestricted use, distribution, and reproduction in any medium, provided the original work is properly cited

Check for updates
Review Article

\section{Cardiomyopathies - The special entity of myocarditis and inflammatory cardiomyopathy}

\author{
Felicitas Escher ${ }^{1-3 *}$, Uwe Kühl ${ }^{1,2}$, Dirk Lassner ${ }^{1}$ and Heinz-Peter \\ Schultheiss ${ }^{1}$
}

${ }^{1}$ Institute for Cardiac Diagnostics and Therapy (IKDT), Berlin, Germany

${ }^{2}$ Department of Cardiology, Charité - Universitaetsmedizin Berlin, Berlin, Germany

${ }^{3}$ DZHK (German Centre for Cardiovascular Research), Partner Site, Berlin, Germany

\section{Introduction}

Cardiomyopathy is a heart muscle disease with structural and functional myocardial abnormalities in the absence of coronary artery disease, hypertension, valvular disease, and congenital heart disease. However, it has become clear that diverse etiologies and clinical manifestations (e.g. arrhythmogenic right-ventricular cardiomyopathy/ dysplasia (ARVC/D), ARVD/C, left-ventricular non-compaction cardiomyopathy (LVNC)) are responsible for the clinical picture of dilated cardiomyopathy (DCM).

The American Heart Association (AHA) classification grouped cardiomyopathies into genetic, mixed and acquired forms, while the European Society of Cardiology (ESC) classification proposed the subgrouping of each major type of cardiomyopathy into familial or genetic, and nonfamilial or nongenetic, forms [1-4].

Cardiomyopathies are clinically heterogeneous diseases, and there are differences in sex, age of onset, rate of progression, risk of development of overt heart failure and likelihood of sudden death within each cardiomyopathy subtype [5].

Because of the complex etiology and clinical presentation, the diagnostic spectrum in cardiomyopathies spans the entire range of non-invasive and invasive cardiological examination techniques including genetic analysis. The exact verification of certain cardiomyopathies necessitates additional investigations. So, histological, immunohistological and molecular biological/virological investigations of endomyocardial biopsies are the gold standard to confirm the diagnosis of an inflammatory cardiomyopathy (DCMi) [6-10].

This review focuses on myocarditis and inflammatory cardiomyopathies underlying an immune-mediated process or persistent viral infection.

The causes

Infectious agents are the major causes of myocarditis and DCMi in diseases of heart muscle Inflammation, triggered by both innate and adaptive arms of the immune response which is primarily required to protect and clear the host of pathogenic infections [11]. The majority of cases of myocarditis and DCMi are subclinical, wherein the pathogen and inflammation are cleared and the afflicted individual dismisses their illness as a case of the flu without any further medical attention. However, what may begin as a productive immune response may deteriorate into chronic immune destruction of the heart muscle, leading to DCMi. 
Several other etiologies of myocarditis and DCMi have also been implicated, including drugs and chemicals, parasites (e.g. in Chagas disease), bacteria or autoimmune phenomena [12-17] (Table 1).

Table 1: Etiology of myocarditis and inflammatory cardiomyopathy

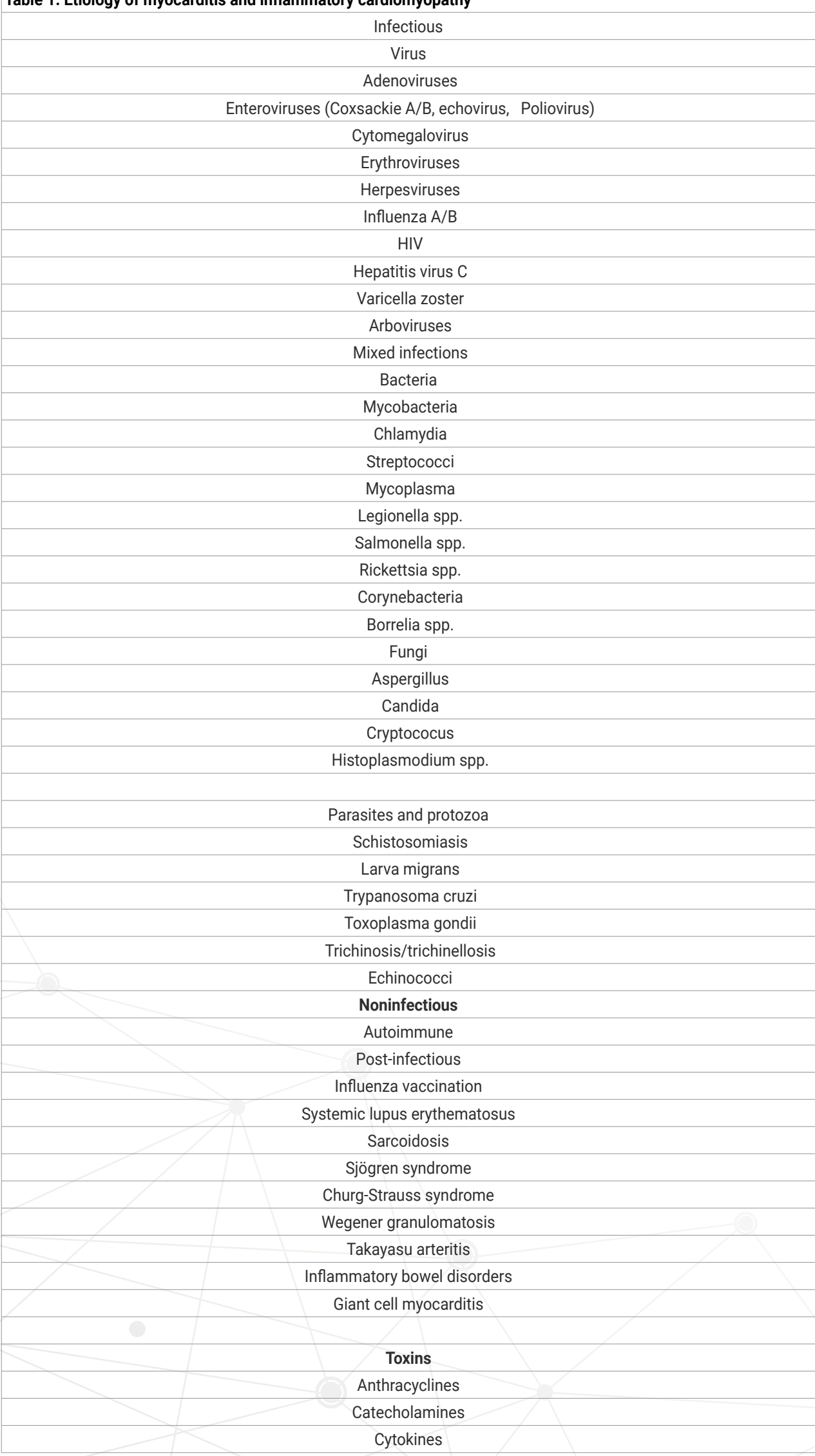




\begin{tabular}{|c|}
\hline Cocaine \\
\hline Alcohol \\
\hline Chemotherapeutic drugs \\
\hline Allergic/hypersensitive \\
\hline Penicillin \\
\hline Tricyclic antidepressants \\
\hline Clozapine \\
\hline Antirheumatic drugs \\
\hline Sulfonamides \\
\hline Cephalosporins \\
\hline
\end{tabular}

\section{Clinical Presentation}

Myocarditis and DCMi are challenging to diagnosis due to the heterogeneity of their clinical presentations $[18,19]$. The clinical presentation of myocarditis and DCMi ranges broadly from subclinical disease with asymptomatic left ventricular dysfunction, chest pain, palpitations and syncopes to fulminant heart failure (79). Myocarditis can manifest like a myocardial infarction, with sudden-onset angina pectoris, arrhythmias and/or heart failure developing within days. Most patients with myocarditis initially have such non-specific symptoms, and these are often categorized in the context of the preceding infection and not as being of cardiac origin. Cardiac involvement is often considered as the differential diagnosis only when cardiac symptoms, such as palpitations, angina, exertional dyspnea or heart rhythm disturbances, persist for a long period after the underlying infection has resolved, or if they develop de novo in the course of the recovery.

The natural history of myocarditis is unpredictable. Patients with acute myocarditis who present with heart failure and mild LV systolic dysfunction normally recover within weeks or months. However, of patients who present with significant LV dysfunction, only $50 \%$ will experience complete resolution; of the remaining patients, $25 \%$ will progress towards chronic systolic dysfunction, while the rest will progress towards end-stage cardiomyopathy resulting in transplantation or death [20].

Taken together, the diagnosis of myocarditis and DCMi is challenging. Therefore, the current expert consensus statement of the ESC maintains that endomyocardial biopsies (EMBs) remains the gold standard for definitive diagnosis of suspected myocarditis and DCMi $[6,8,9]$. Consequently, it is essential that in addition to histology, samples must be analyzed by immunohistology and molecular biology to determine the etiology of the disease as a basis for an etiology-specific treatment. In this context, it is important to recognize that dilated cardiomyopathy (DCM) is the most serious outcome of myocarditis. Retrospective studies have shown that 30-70\% of DCM cases have suffered from previous viral myocarditis.

In addition, it is important to realize that idiopathic cardiomyopathy is more frequently seen in younger patients ( $<40$ years) than elderly patients (63\% vs. $7 \%$ ) [20].

\section{The diagnosis}

Principally non-invasive techniques are useful and necessary to suspect the to diagnose of acute or chronic myocarditis. However, EMB is be the gold standard for the definitive diagnosis of myocarditis and DCMi in the acute and chronic stage of the disease [6].

\section{Electrocardiogram}

All patients with suspected myocarditis should receive a 12-lead electrocardiogram. Electrocardiographic findings in myocarditis patients include T-wave and ST-segment changes, including ST-segment elevation mimicking acute myocardial infarction or 
conduction. However, these changes are neither sensitive nor specific for the diagnosis of myocarditis and DCMi and can also be found in other severe clinical settings.

\section{Imaging techniques}

Echocardiography remains the key method for analyzing ventricular function in suspected myocarditis and helps to rule out other entities as well. Thus, all patients with suspected myocarditis or DCMi should undergo echocardiographic studies at presentation and during follow-up.

Regarding patients with preserved left ventricular ejection fraction (LVEF), speckle tracking is a promising tool. In patients with biopsy-proven myocardial inflammation, global longitudinal strain rate and global longitudinal strain are significantly impaired compared with patients without inflammation, regardless of conventional echocardiographic parameters. Therefore, this technique has a higher sensitivity in the detection of mild myocardial damage in patients with preserved LVEF [21,82].

Cardiac magnetic resonance (CMR) can help to confirm the suspicious diagnosis of acute myocarditis. The combined use of three different CMR techniques are recommended, and findings are compatible with myocardial inflammation if at least two Lake Louise criteria are met. The Lake Louise criteria include hyperemia, edema, and necrosis. When at least two criteria are met, a sensitivity of $76 \%$ and specificity of $96 \%$ have been reported in patients with clinically suspected acute myocarditis and pseudo-infarction presentation. However, they do not provide any information on the type of infectious pathogen or inflammation, nor whether the infectious strain has been completely eliminated or the inflammation has subsided. Moreover, obtaining a biopsy from the region of late gadolinium enhancement of the CMR has not been shown to increase the yield of diagnosis [22] and, in chronic myocarditis, the diagnostic performance of CMR has been found to be significantly worse (sensitivity, 63\%; specificity, 40\%) [23]. Therefore, CMR is not appropriate for making a definitive diagnosis nor for guiding clinical management in chronic myocarditis/DCMi.

In sum, CMR is a promising technology. However, the sensitivity for the diagnosis of myocarditis, especially in the chronic phase of the disease, is scarce. Furthermore, detailed information regarding the mechanisms and etiology of intramyocardial inflammation and/or viral persistence cannot be generated by CMR. Therefore, the diagnostic relevance of CMR in DCMi is significantly limited [80].

\section{Biomarkers}

The usefulness of viral serologies is limited, especially in chronic myocarditis or inflammatory cardiomyopathy, as IgG antibodies for cardiotropic viruses can be found in the blood stream of the general population without accompanying cardiac involvement.

Many distinct cardiac autoantibodies e.g. against $\alpha$-myosin, $\beta$-myosin heavy chain, $B$ adrenergic receptor, and cardiac troponin have been identified. Although in mouse models immunization with these antigens can induce myocarditis and show by progression of myocardial fibrosis remodeling that leads to DCM, the clinical significance regarding pathophysiological mechanisms are still not proven $[12,18,81]$.

\section{Endomyocardial biopsy}

Endomyocardial biopsy remains the gold standard for the diagnosis of myocarditis and DCMi. Endomyocardial biopsy is the only diagnostic tool for establishing etiological diagnosis (viral or immune-mediated) in myocarditis and DCMi [24]. Therefore, this implies that all patients with suspected myocarditis should undergo an EMB, according to the position statement of the ESC [6]. Current guidelines of the AHA recommend EMB only in a limited number of clinical scenarios, which do not include some common 
presentations of myocarditis - in particular, pseudo-infarction [25]. However, the ESC working group on myocardial and pericardial diseases recommend in their statement position paper that in all patients fulfilling the diagnostic criteria for clinically suspected myocarditis, selective coronary angiography and EMB should be performed [6]. Endomyocardial biopsy can confirm the diagnosis of acute and chronic myocarditis and identify the underlying etiology - virus and/or the type of inflammation - which imply different treatments and prognoses. An incomplete diagnosis may provide an incomplete picture of the disease and thus lead to misinterpretations and possibly incorrect treatment decisions that might be deleterious for the patient.

Regarding the standardized diagnostic criteria, histopathology and immunohistopathology methods are the current gold standard by which the diagnosis of myocarditis and DCMi is made [26-29]. Furthermore, the evaluation of EMBs for viral persistence is essential, as the prospective evaluation of patients showed that mortality and progression to end-stage DCMi was significantly increased in those patients with residual viral genomes in the myocardium. Furthermore, it was shown that the persistence of viral genomes in repeated EMBs was associated with progressive LV dysfunction [30].

Endomyocardial biopsy can be performed with a very low major complication rate when performed by experienced operators. In experienced hands, left ventricular biopsy is as safe as right ventricular biopsy [31].

A basic prerequisite for a clinically relevant biopsy diagnostic is the removal of a sufficient number of biopsies (6 to 8) and high-quality tissue samples from different areas of the myocardium. If the sample predominantly contains thrombus, fat or connective tissue, additional samples must be collected. Apart from specific conditions such as arrhythmogenic right-ventricular dysplasia, in which the characteristic tissue changes mainly occur in certain myocardium areas of the right ventricle, the tissue diagnostic has a similar sensitivity for left or right ventricular biopsy [32].

Histological analysis

The histological examination of paraffin sections by different staining protocols (HE, EvG, PAS, Azan) is used to detect myocardial cell death, scars, fibrosis, disarrays, cardiomyocytechanges, pathological vascular conditions, granulomas and inflammatory cell differentiation. Storage disorders such as amyloidosis, iron deposits, glycogen and others can be excluded or specified by additional staining (e.g., immunohistochemical differentiation of amyloid subtypes and optional electron microscopic analysis) [26]. The EMB diagnosis of myocarditis is based on histomorphological criteria according to the Dallas classification [33]. Active myocarditis is defined by the simultaneous detection of inflammatory infiltrates and the presence of myocytolysis. Borderline myocarditis is used when the infiltrates are present without myocytolysis (Figure 1).

Immunohistochemical examination on intramyocardial inflammation

Whereas the light microscopy-based Dallas criteria are limited by high interobserver variability in interpreting biopsy specimens, the use of immunohistochemistry markedly increased the number of EMB-revealing diagnoses of myocarditis and DCMi. According to the ESC definition, myocarditis is present with immunohistological detection of the following abnormal inflammatory infiltrates: $\geq 14$ leucocytes $/ \mathrm{mm}^{2}$, including up to 4 monocytes $/ \mathrm{mm}^{2}$ with the presence of CD3-positive T-lymphocytes $\geq$ 7 cells $/ \mathrm{mm}^{2}$. Currently, however, the use of different monoclonal antibodies allows for the exact characterization and localization of the cell infiltrates and cell adhesion molecules, both of which are relevant for the prognosis (e.g., CD3, CD11a (LFA-1), CD11b (MAC-1)/M2, CD45R0 (memory or activated lymphocytes) and perforin-positive cytotoxic lymphocytes) and increased expression of adhesion molecules CD54 (ICAM), CD106 (VCAM) and HLA-1/HLA-DR as markers for tissue activation (Figures 2,3). 

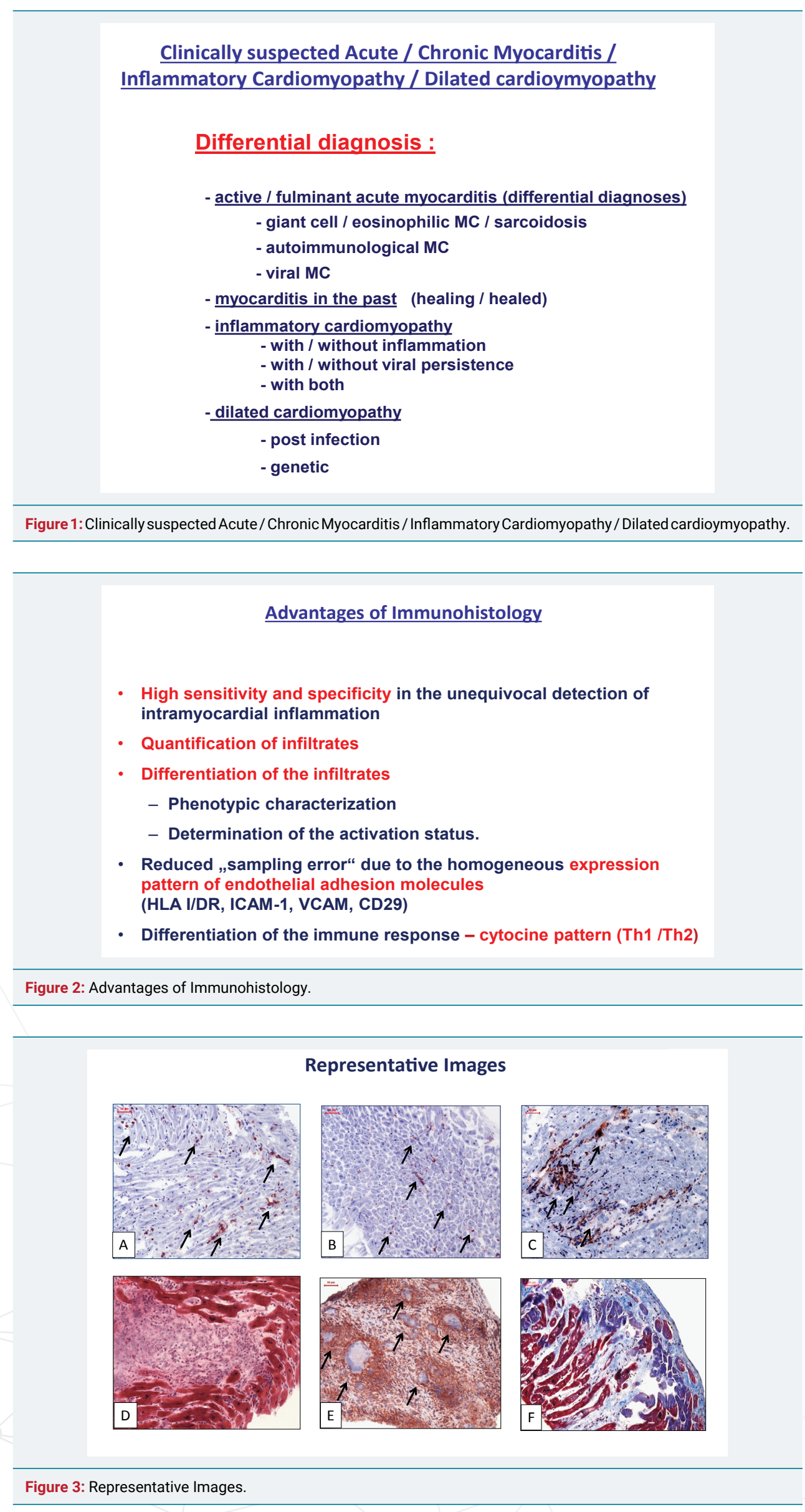


\section{Molecular virology for the detection of myocardial infections}

For decades, coxsackieviruses - and, to a lesser extent, adenoviruses - have been well established in pediatric and adult myocarditis and chronic heart muscle disease. Furthermore, distinct genotypes of erythroviruses, including erythroparvovirus B19, human herpesvirus type 6 (HHV6A/B), human immune deficiency virus (HIV), cytomegalovirus (CMV), herpes simplex type 2 virus and hepatitis $C$ virus, have been identified with varying degrees of frequency in cardiac tissues [34-36].

Microbial genomes are determined, quantified and sequenced using PCR-based methods. The current viral load monitoring for an effective treatment is performed by quantitative PCR. The transcriptional activity of a virus in myocardial tissue or peripheral blood cells is routinely determined by nested-RT-PCR and QPCR for the two most frequent cardiotropic viruses: erythroparvovirus and HHV-6. Patients with active erythroparvoviral infections reported a higher frequency of chest pain and reduced systolic left ventricular ejection fraction, accompanied by a left ventricular end-diastolic diameter increase [37].

\section{Gene profile analysis}

Idiopathic giant cell myocarditis (GCM), cardiac sarcoidosis (CS) and eosinophilic myocarditis are rare disorders that cause cardiomyopathy [38-40]. Both GCM and CS are generally rapidly progressive, despite treatment with standard heart failure and arrhythmia therapies. Making the diagnosis of GCM or CS by means of myocardial tissue is required. However, the main problem is the sampling error. Furthermore, for pathologists, discriminating between idiopathic GCM and CS is difficult. In a previous study, Lassner et al., identified distinct differential profiles that allowed for a clear discrimination between tissues harbouring giant cells and those with acute myocarditis or inflammation-free controls [41]. Therefore, myocardial gene expression profiling is a reliable method for predicting the presence of multinuclear giant cells in the myocardium - even without direct histological proof - in single, small EMB sections, and thus reduces the risk of sampling errors (Figure 4).

\section{Gene profiling as a new diagnostic approach}

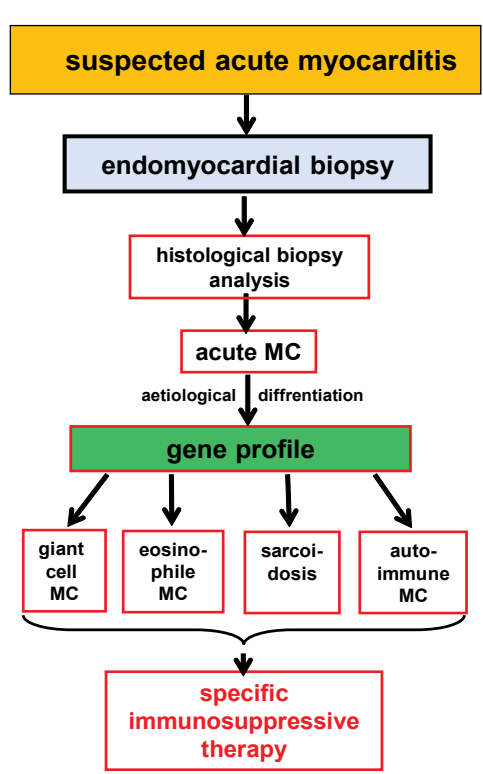

Figure 4: Gene profiling as a new diagnostic approach. 


\section{Prognosis}

Prognosis of myocarditis and DCMi depends on etiology, clinical presentation and disease stage. Myocarditis and DCMi patients can have partial or full clinical recovery; some may relapse many years after the first episode $[42,43]$. The clinical presentation of acute myocarditis ranges broadly from subclinical disease to fulminant heart failure.

Viral infection: The persistence of viral infection of Entero/and Adenovirus in the myocardium has been associated with ventricular dysfunction, while viral genome clearance has been associated with improvement of ventricular function and a better 10-year prognosis. Since different viruses and viral subtypes respond differently to antiviral medications and are in some cases not completely eliminated, this information is important for making a tailored decision regarding treatment and the success thereof [44].

The clinical impact of vasculotropic erythroparvovirus B19 in the heart is still under discussion [45-47]. Erythroparvovirus B19 can hibernate in endothelial precursor cells after primary infection. After this, the virus infects the cardiac endothelium. The virus exerts its pathogenic effects by transcriptional activity, the activation of the immune system and the induction of apoptosis, which leads to endothelial dysfunction. This compromises tissue perfusion, causing chronic ischemia and diastolic/systolic dysfunction. This process is also marked by upregulation of adhesion molecules which home T-lymphocytes to the myocardium [48-51,86]. Thus, although erythroparvovirus B19 does not directly infect cardiomyocytes like coxsackievirus or adenovirus, the downstream effects of endothelial cell infection can induce LV dysfunction.

Human herpesvirus 6A and 6B (HHV-6A/B) are possible pathogenetic causes of myocarditis and idiopathic-cardiomyopathy subsets [52]. The prevalence of chromosomally integrated HHV-6 (ciHHV-6) is approximately 0.8\% of HHV-6-positive endomyocardial biopsies. Identifying individuals with ciHHV-6 is important because the complete HHV- 6 genome is present in every cell of their bodies $[53,54]$ and a permanent reactivation of this virus in all tissues is assumed to occur. Detection of ciHHV-6 is only possible by QPCR. Persistently high viral loads of HHV-6 genomes in blood cells or tissues confirm the presence of ciHHV-6. The elimination of the chromosomally integrated virus is currently impossible but the transcriptional activity of ciHHV- 6 can be reduced under treatment with an antiviral drug. Monitoring of the viral RNA load is the best indicator for an effective therapy or for the reactivation of ciHHV-6.

Intramyocardial Inflammation: In a previous study, immunohistological evidence of inflammation was identified as an independent predictor of survival. Moreover, the exact characterization and quantification of intramyocardial infiltration is relevant for the prognosis. Histology on paraffin sections and parallel immunohistochemical analyses on cryosections by a set of 6-8 specific antibody-staining inflammatory cells and adhesion molecules for subsequent digital imaging analysis allow for the characterisation of acute and chronic myocarditis without relevant sampling error. Highly prognostic parameters (CD3, perforin, CD45R0) are included which can predict the long-term outcome of patients at the time of their initial biopsies. Recently, we demonstrated that the presence of cytotoxic perforin-positive myocardium-infiltrating cells could predict an adverse LVEF course over a long follow-up period in a large cohort of 495 DCMi patients. This was the first report to elucidate the prognostic impact of perforin-positive cells for the outcome of DCMi patients and indicates that the exact characterization and quantification of intramyocardial infiltrates has clinical value for the assessment of long-term LVEF prognosis in DCMi [55]. These data should be helpful for cardiologists starting immunosuppressive therapy earlier in high-risk patients.

Fibrosis: Fibrosis is a fundamental process observes in non-ischemic cardiomy- 
opathies. This mostly perivascular and interstitial reactive fibrosis is mainly caused by persistent and local inflammation and cardiomyocyte death which induced the conversion of fibroblasts into myofibroblasts. Several other players are also involved like interleukins (e.g. IL 17/23) and Transforming growth factor (TGF) $\beta$ stimulating several other growths factors (56-62). Furthermore, alterations of the myocardial extracellular matrix by matrix metalloproteinases (MMPs) and tissue inhibitors of matrix metalloproteinases (TIMPs) are observed.

The extent of myocardial fibrosis has prognostic implications as it is responsible for contractile dysfunction and arrhythmias and it is a major cause of heart failure progression [63].

\section{Gene mutations in cardiomyopathies}

Current guidelines recommend genetic screening (evidence level A) for ARVD/C, hypertrophic cardiomyopathy (HCM), LVNC and DCM [64,65]. Next generation sequencing (NGS) technologies has made a new era in human genetics and will enable more labs to perform genetic testing. However, for the interpretation of genetic data great experience is needed as distinction between pathogenetic and non-pathogenetic genes remains a difficult and unresolved issue.

Molecular diagnostics and genetic testing are helpful and necessary for therapeutic and preventive decisions. In particular, they allow for early detection of disease development and better family counselling. One actual aspect is the deciphering of the interrelationship of genetic pathways with other non-genetic disease mechanisms, including immunological or infectious etiologies [7,64].

\section{Treatment options}

The mainstay of treatment for DCM/DCMi is an optimal heart failure medical regimen. The main aim is to reduce symptoms of heart failure and to improve cardiac function. In this context several pharmacological options and devices are available, summarized in the ESC guidelines for treatment of heart failure with reduced ejection fraction [83]. If the patient does not recover, then cardiac transplantation or implantation of long-term mechanical assist is the last option.

In the case of myocarditis and DCMi, there are specific, etiology-driven therapeutic options (Table 2). Endomyocardial biopsies serve as the basis for these specific and causal medical therapy $[66,67]$.

\section{Antiviral treatment}

Interferon-beta: Interferons serve as a natural defense against many viral infections. Their innate production is associated with clinical recovery from viral infection and subsequent sequelae, while exogenous administration is protective. Clinical and experimental data have shown that TLR3 signaling is essential for the prognosis. Individuals harboring TLR3 variants have abundant innate immune response to enteroviral infection, leading to reduced viral clearance and an increased risk of cardiac pathology in this context. Type I interferons therefore constitute a promising choice for treatment of chronic viral cardiomyopathy $[84,85]$.

Enterovirus and adenovirus infections respond well to interferon beta (IFN- $ß$ ) [68]. In a non-randomized study, it was shown that the administration of IFN- $\beta$ favors viral clearance and reduces the progression of virus-induced myocardial injury with improved long-term survival. The treatment scheme in chronic viral cardiomyopathy closely follows the progress gained in multiple sclerosis. An initial dose of $2 \times 10^{6}$ IU IFN- $\beta$ is administered subcutaneously every other day and increased at weekly intervals, first to $4 \times 10^{6} \mathrm{IU}$ and then to $6-8 \times 10^{6} \mathrm{IU}$; this is continued for 24 weeks. The symptomatic treatment for heart failure is maintained. 


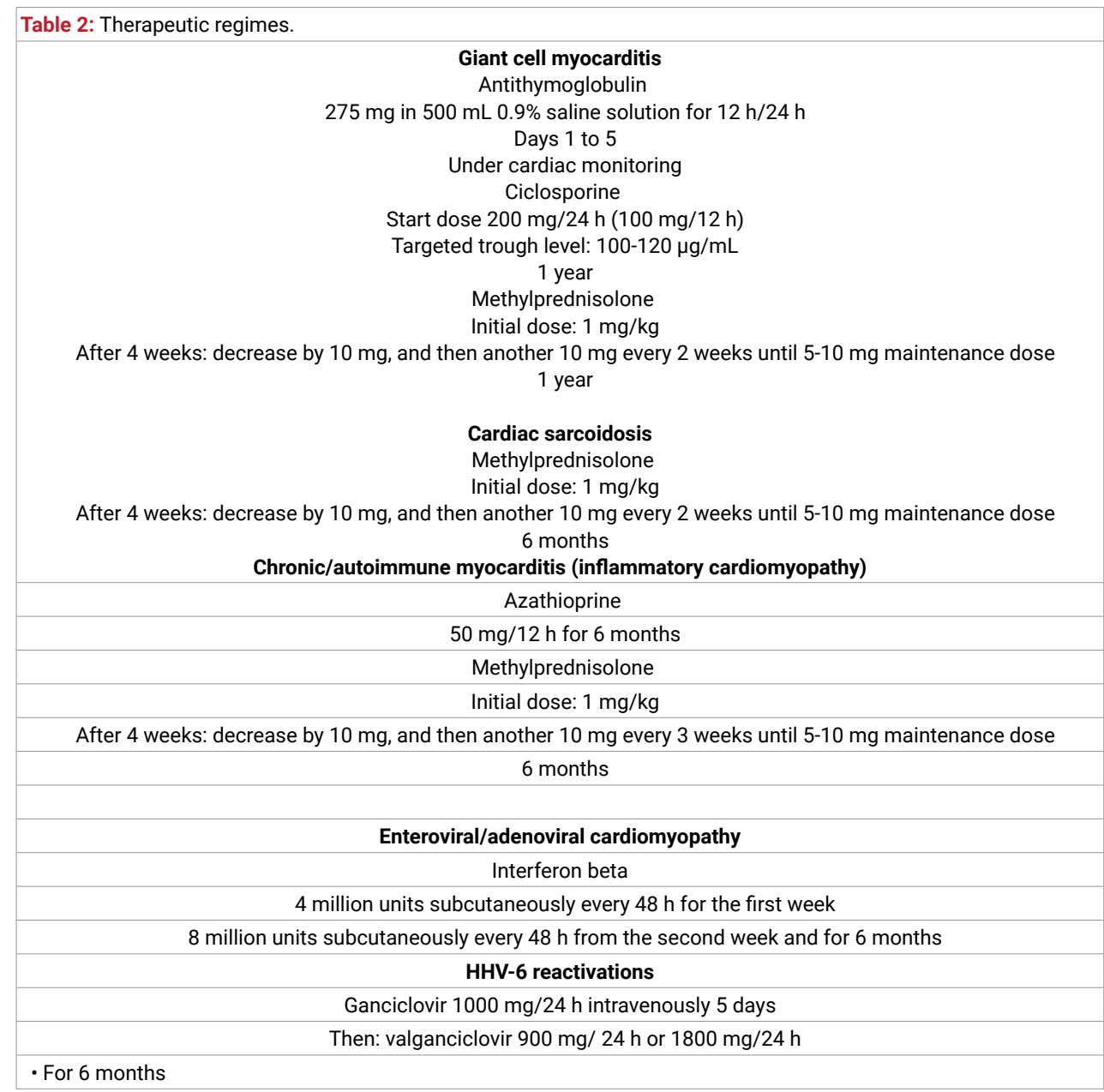

In a Phase 2 study - betaferon in a chronic viral cardiomyopathy (BICC) trial 143 patients with symptoms of heart failure and biopsy-based confirmation of the enterovirus, adenovirus, and/or erythroparvovirus B19 genomes in their myocardial tissue were randomly assigned to double-blind treatment, and received either a placebo $(n=48)$ or $4 \times 10^{6}(n=49)$ and $8 \times 10^{6} \mathrm{IU}(n=46)$ IFN- $\beta$ for 24 weeks, in addition to standard heart failure treatment. Patients with active myocarditis or other specific causes of heart failure were excluded. Compared to the placebo, virus elimination and/or virus load reduction was higher in the IFN- $\beta$ groups (odds ratio $2.33, p=0.048$ ), similarly to both interferon groups and both strata. IFN- $\beta$ treatment was associated with favorable effects on NYHA functional class ( $p=0.013$ at follow-up Week 12), improvement in quality of life (Minnesota Heart Failure score; $p=0.032$ at follow-up Week 24), and patient global assessment (follow-up Week 12 to follow-up Week 24; $p=0.039$ ). The frequency of adverse cardiac events was not higher in the IFN- $\beta$ groups compared to the placebo group [69] (Figure 5).

Other successful reports for the treatment of viral myocarditis include ganciclovir in the case of cytomegalovirus and chromosomally integrated HHV-6 virus, and antihepatitis C (HCV) combination therapy in HCV-positive patients [70].

Erythroparvovirus B19 monoinfection is found in about 42\%, and with replicative intermediates in about $25 \%$ of endomyocardial biopsies [87]. Experimental studies showed that a thymidine analogue Telbivudine reduced erythoparvovirus-induced apoptosis of circulating angiogenetic cells thus protecting susceptible cells from cell death [71]. An actual analyzed treatment trial in patients treated with Telbivudine indicates that treatment suppresses viral replicative intermediates, improves clinical outcome and reduces myocardial inflammation (unpublished data). A clinical prospective-randomized study has to be scheduled to evaluate the results. 
Improvement of entero-virus positive myocarditis by interferon- $ß$ treatment

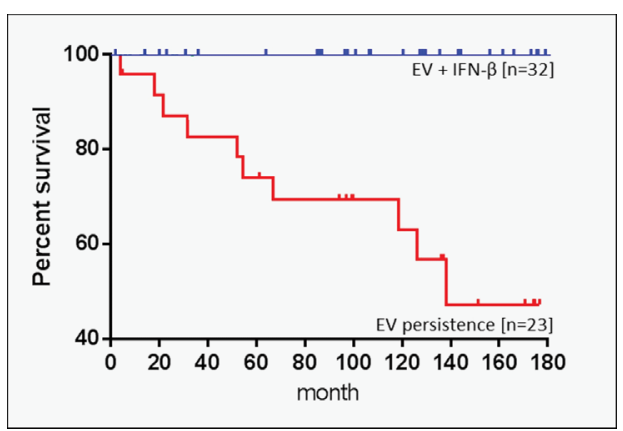

Figure 5: Mortality rate among patients positive for enterovirus (EV) infection: unadjusted survival according to virus analysis at follow-up. Interferon- $\beta$-induced ( 6 month treatment) enterovirus clearance was associated with a significantly reduced mortality rate in comparison to patients who had enterovirus persistence $(p=0.0005$ by the log-rank test). Modified by Kühl, Schultheiss et al. J Am Coll Cardiol. 2012 Oct 2;60(14):1295-6.

Immunosuppressive treatment

Currently available data show that immunosuppressive therapy in patients with biopsy-proven, virus-negative inflammatory cardiomyopathy is an effective and safe option for recovery from cardiac failure in carefully selected patients [66]. Administered anti-inflammatory drugs include corticosteroids, azathioprine and cyclosporine, which are administered in addition to regular heart failure medication.

$\alpha$-Methylprednisolone is generally given at a dose of $1 \mathrm{mg} / \mathrm{kg}$ body weight, initially for four weeks. Depending on body weight, azathioprine is administered at a dose of $100-150 \mathrm{mg}$ daily in addition to the corticosteroid. The steroid dosage is titrated down every two weeks in 10-mg increments until a maintenance dose of $10 \mathrm{mg}$ is reached. The treatment duration should last for three to six months. Actual data from the first randomized trials confirm the efficacy of these treatment regimens in carefully selected patients $[72,73]$.

In a recently published randomized trial (TIMIC study), the authors confirmed a positive treatment response in patients with virus-negative chronic active myocarditis. Eighty-eight percent showed an improvement in cardiac function and dimensions, defined as an increase of $>10$ percentage points in the absolute $\mathrm{EF}$ and a reduction of LV end-diastolic volume (EDV) or LV end-diastolic diameter (EDD). None of the untreated patients showed a 6-month improvement of LVEF, which significantly worsened compared with the baseline.

However, it has been mentioned that immunosuppressive treatment of patients with virus-positive myocarditis or DCMi is deleterious, as was shown via a retrospective analysis conducted by Frustaci et al. [74]. These data underline the importance of determining the etiology of myocarditis or DCMi before starting an immunosuppressive treatment regimen.

The positive result was confirmed in our EMB-based retrospective analysis of virusnegative DCMi patients, where immunosuppressive treatment showed effectiveness and beneficial effects even after a long-term follow-up period (up to 10 years). The majority of patients improved significantly with LVEF, especially those with noticeably enhanced baseline inflammation [75] (Figure 6).

Intravenous immunoglobulin treatment

Case reports and small pilot studies showed a significant improvement of LV function in myocarditis and pediatric patients after treatment with intravenous immunoglobulins (IVIGs). However, a randomized, double blind, placebo-controlled 
Clinical course and results of patients treated with immunosuppressive therapy at baseline, after 6-month and long term follow-up (up to 10 years)
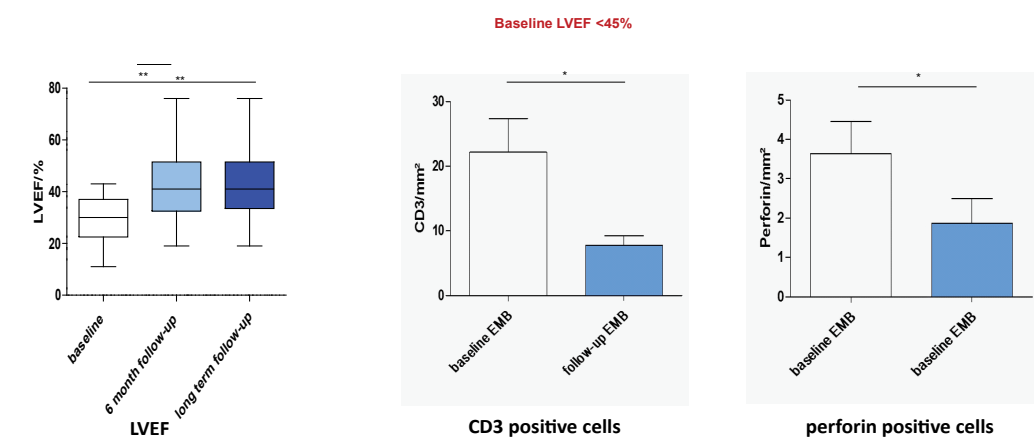

Figure 6: Hemodynamic course of patients with virus-negative inflammatory cardiomyopathy treated immunosuppressive at baseline, 6 months and at a long-term follow-up period.

We analyzed the hemodynamic course of 87 patients after 6 months and in long-term follow-ups subsequent to immunosuppressive therapy: $1 \mathrm{mg} / \mathrm{kg}$ body weight daily of prednisone for 4 weeks followed by $0.33 \mathrm{mg} / \mathrm{kg}$ body weight daily for 5 months and azathioprine $2 \mathrm{mg} / \mathrm{kg}$ body weight daily for 6 months.

Immunosuppressive treatment of patients with virus-negative inflammatory cardiomyopathy resulted in A) an improvement of LVEF in long-term follow-up with significantly reduction of intramyocardial inflammation B) CD3 positive t-cells, C) cytotoxic cells (perforin) in 6 month EMB.

Mean values \pm standard deviation are shown; ${ }^{*} P<0.0001$, ${ }^{*} P<0.05$ (compared to baseline EMB).

trial with IVIGs did not offer an advantage in treating DCM over a placebo [76]. The variation in efficacy may be due to the heterogeneity of the disease etiology, which was not proven. Therefore, there is a need for further research.

Immunoadsorption

Immunoadsorption may represent an additional therapeutic option [77]. However, we are waiting for the results of a prospective randomized study which is underway so far there are conflicting results regarding its effectiveness.

\section{Conclusion}

Myocarditis and DCMi typically result from infection by a cardiotropic virus followed by inflammatory destruction of the myocardium. As disease entities, myocarditis and DCMi characterization has been hampered by their heterogeneous clinical presentations and diverse etiologies. In the early stage of the diseases, both the infectious trigger and the resulting immune response may already cause irreversible myocardial injuries that influence acute and long-term outcomes. If the infectious agent is rapidly eliminated and the inflammatory process is resolved in a timely manner, the disease will resolve with no or only minor alterations of the myocardium.

Chronic myocardial injury in viral myocarditis develops if the antiviral immune response fails to eliminate theinfectious agent completely or if the chronic inflammatory process does not resolve properly despite virus clearance. In such conditions, the long-term outcome depends on the nature and extent of the virus-affected tissue compartments, which vary considerably with the amount and kind of infectious agent or the number and subtype of the smoldering cellular inflammatory infiltrates. In addition to the initial irreversible tissue alterations, persistent viruses and postinfectious immune or autoimmune processes may induce persistent or progressive ventricular dysfunction, arrhythmias and symptomatic cardiac complaints.

Apart from heart failure therapies, there are alternatives for etiologically driven specific treatment in myocarditis and DCMi. Because the clinical course of myocarditis and DCMi is based on unpredictable non-inversive techniques, all patients with clinically suspected myocarditis and DCMi must undergo endomyocardial biopsy 
before irreversible and thus untreatable damage to the myocardium occurs. The exact analysis and quantification of intramyocardial infiltrates as well as the diagnosis of viral pathogens has high clinical value for the assessment of long-term LVEF prognosis and is essential for initiating a specific therapy (Figure 7). Immunomodulatory IFN- $\beta$ treatment is a well-tolerated and safe treatment option, leading to effective virus clearance or reduction of the virus load in patients with coxsackie- and adenoviruspositive cardiomyopathy. Favorable clinical effects assess quality of life, NYHA functional class, and patient global assessment and survival. Preliminary data show a positive effect of Telbivudine in erythroparvovirus positive patients with replicative intermediates. Immunosuppressive treatment in virus-negative DCMi showed effectiveness and beneficial effects even after a long-term follow-up period.

Finally, the understanding of the pathophysiological mechanisms of myocarditis and DCMi based on the analysis of endomyocardial biopsies is crucial for development of new and specific therapeutics. Recently identified immune factors like IL 17 and advances in the understanding of the function of matrix metalloproteinases yield another target for altering disease progression [78]. Thus, beside the proper diagnosis, the better understanding of the mechanisms surrounding the etiologies are essential for the development of new diagnostics and therapeutically rudiments.

\section{Conflict of Interest}

The authors declare that no conflict of interest exists. The research projects used as the basis for the review article were funded by the German Research Foundation (DFG) in the context of Sonderforschungsbereich-Transregio (SFB-TR19) and inflammatory cardiomyopathy, and a grant of ERA-Net on Cardiovascular Diseases (ERA-CVD; JTC2016-40-158).

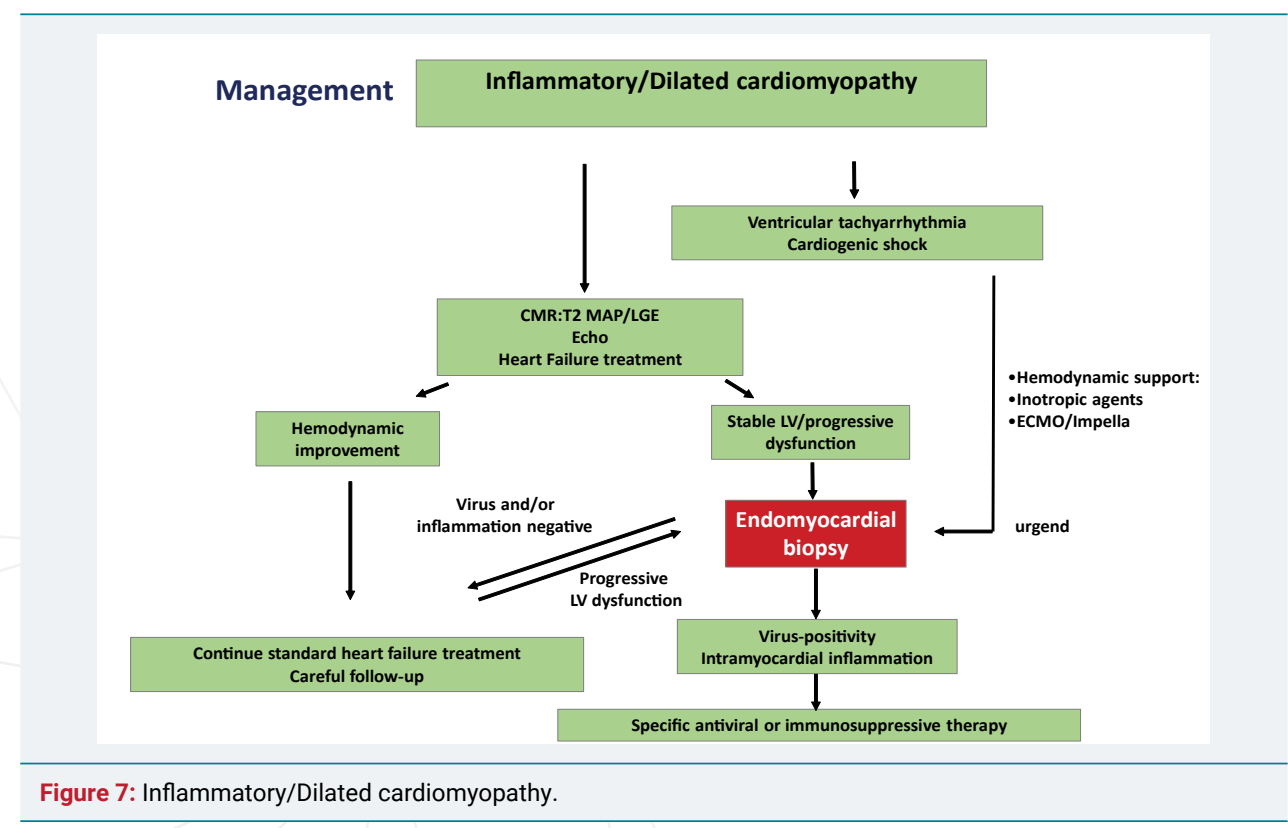

\section{References}

1. Maron BJ, Towbin JA, Thiene G, Antzelevitch C, Corrado D, et al. Contemporary definitions and classification of the cardiomyopathies: an American Heart Association Scientific Statement from the Council on Clinical Cardiology, Heart Failure and Transplantation Committee; Quality of Care and Outcomes Research and Functional Genomics and Translational Biology Interdisciplinary Working Groups; and Council on Epidemiology and Prevention. Circulation. 2006; 113: 1807-1816. Ref.: http://bit.ly/2LuKdbV

2. Elliott $P$, Andersson $B$, Arbustini E, Bilinska Z, Cecchi F, et al. Classification of the cardiomyopathies: a position statement from the European Society of Cardiology Working Group on Myocardial and Pericardial Diseases. Eur Heart J. 2008; 29: 270-276. Ref.: http://bit.ly/2LuE1AC 
3. Braunwald E. Cardiomyopathies: An Overview. Circ Res. 2017; 121: 711-721. Ref.: http://bit.ly/2ZXH8VJ

4. McKenna WJ, Maron BJ, Thiene G. Classification, Epidemiology, and Global Burden of Cardiomyopathies. Circ Res. 2017; 121: 722-730. Ref.: http://bit.ly/3210w65

5. Rose NR, Cihakova D. Cardiomyopathies. Autoimmunity. 2004; 37: 347-350.

6. Caforio AL, Pankuweit S, Arbustini E, Basso C, Gimeno-Blanes J, et al. Current state of knowledge on aetiology, diagnosis, management, and therapy of myocarditis: a position statement of the European Society of Cardiology Working Group on Myocardial and Pericardial Diseases. Eur Heart J. 2013; 34: 2636-2648. Ref.: http://bit.ly/2xml1uJ

7. Schultheiss HP, Kuehl U, Cooper LT. The Management of Myocarditis. Eur Heart J. 2011; 32: 26162665. Ref.: http://bit.ly/2XJir1G

8. Sagar S, Liu PP, Cooper LT. Myocarditis. Lancet. 2013; 379: 738-747. Ref.: http://bit.ly/2WTHXNx

9. Calabrese F, Thiene G. Myocarditis and inflammatory cardiomyopathy: microbiological and molecular biological aspects. Cardiovasc Res. 2003; 60: 11-25. Ref.: http://bit.ly/2XfjgQy

10. Pollack A, Kontorovich AR, Fuster V, Dec GW. Viral myocarditis--diagnosis, treatment options, and current controversies. Nat Rev Cardiol. 2015; 12: 670-680. Ref.: http://bit.ly/323VPZ5

11. Bracamonte-Baran W, Čiháková D. Cardiac Autoimmunity: Myocarditis. Adv Exp Med Biol. 2017; 1003: 187-221. Ref.: http://bit.ly/2RMeJ1U

12. Schultheiss HP, Fairweather D, Caforio ALP, Escher F, Hershberger RE, et al. Dilated cardiomyopathy. Nat Rev Dis Primers. 2019; 5: 32. Ref.: http://bit.ly/2XktA90

13. Rapezzi C, Arbustini E, Caforio AL, Charron P, Gimeno-Blanes J, et al. Diagnostic work-up in cardiomyopathies: bridging the gap between clinical phenotypes and final diagnosis. A position statement from the ESC Working Group on Myocardial and Pericardial Diseases. Eur Heart J. 2013; 34: 1448-1458. Ref.: http://bit.ly/2YolOnd

14. Agrawal N, Khunger A, Vachhani P, Colvin TA, Hattoum A, et al. Cardiac Toxicity Associated with Immune Checkpoint Inhibitors: Case Series and Review of the Literature. Case Rep Oncol. 2019 21; 12: 260-276. Ref.: http://bit.ly/2J0b8L6

15. Merlo M, Cannatà A, Gobbo M, Stolfo D, Elliott PM, et al. Evolving concepts in dilated cardiomyopathy. Eur J Heart Fail. 2018; 20: 228-239. Ref.: http://bit.ly/2JgyScQ

16. Weintraub RG, Semsarian C, Macdonald P. Dilated cardiomyopathy. Lancet. 2017; 390: 400-414. Ref.: http://bit.ly/2XILZTN

17. Trachtenberg BH, Hare JM. Inflammatory Cardiomyopathic Syndromes. Circ Res. 2017; 121: 803818. Ref.: http://bit.ly/2FLdsU9

18. Caforio AL, Marcolongo R, Basso C, Iliceto S. Clinical presentation and diagnosis of myocarditis. Heart. 2015; 101: 1332-1344. Ref.: http://bit.ly/2LvK8Vd

19. Liu PP, Schultheiss HP. Myocarditis. In: Braunwald ed, Heart Disease. 8 ed. Philadelphia: W B Saunders co; 2008; 1775-1792.

20. Heymans S, Eriksson U, Lehtonen J, Cooper LT Jr. The Quest for New Approaches in Myocarditis and Inflammatory Cardiomyopathy. J Am Coll Cardiol. 2016; 68: 2348-2364. Ref.: http://bit.ly/2J0QF8S

21. Escher F, Kasner M, Kühl U, Heymer J, Wilkenshoff U, et al. New echocardiographic findings correlate with intramyocardial inflammation in endomyocardial biopsies of patients with acute myocarditis and inflammatory cardiomyopathy. Mediators Inflamm. 2013; 2013: 875420. Ref.: http://bit.ly/2NpKyPR

22. Lurz P, Luecke C, Eitel I, Föhrenbach F, Frank C, et al. Comprehensive Cardiac Magnetic Resonance Imaging in Patients With Suspected Myocarditis: The MyoRacer-Trial. J Am Coll Cardiol. 2016; 19; 67: 1800-1811. Ref.: http://bit.ly/2ZYyvdA

23. Friedrich MG, Sechtem U, Schulz-Menger J, Holmvang G, Alakija P, et al. International Consensus Group on Cardiovascular Magnetic Resonance in Myocarditis, et al. Cardiovascular magnetic resonance in myocarditis: A JACC White Paper. J Am Coll Cardiol. 2009; 53: 1475-1487. Ref.: http://bit.ly/2Yot4Et

24. Thiene G, Bruneval P, Veinot J, Leone O. Diagnostic use of the endomyocardial biopsy: a consensus statement. Virchows Arch. 2013; 463: 1-5. Ref.: http://bit.ly/2J19LMg

25. Cooper LT, Baughman KL, Feldman AM, Frustaci A, Jessup M, et al. The role of endomyocardia biopsy in the management of cardiovascular disease. Eur Heart J. 2007; 28: 3076-3093. Ref.: http://bit.ly/2LupzsC 
26. Leone O, Veinot JP, Angelini A, Baandrup UT, Basso C, et al. 2011 consensus statement on endomyocardial biopsy from the Association for European Cardiovascular Pathology and the Society for Cardiovascular Pathology. Cardiovasc Pathol. 2012; 21: 245-274. Ref.: http://bit.ly/2Lt4ej6

27. Basso C, Calabrese F, Angelini A, Carturan E, Thiene G. Classification and histological, immunohistochemical, and molecular diagnosis of inflammatory myocardial disease. Heart Fail Rev. 2013; 18: 673-681. Ref.: http://bit.ly/303njwl

28. Thiene G, Bruneval P, Veinot J, Leone O. Diagnostic use of the endomyocardial biopsy: a consensus statement. Virchows Arch. 2013; 463: 1-5. Ref.: http://bit.ly/2J19LMg

29. Ishibashi-Ueda H, Matsuyama TA, Ohta-Ogo K, Ikeda Y. Significance and Value of Endomyocardial Biopsy Based on Our Own Experience. Circ J. 2017; 24; 81: 417-426. Ref.: http://bit.ly/2Nlyzm5

30. Kühl U, Pauschinger M, Noutsias M, Seeberg B, Bock T, et al. High prevalence of viral genomes and multiple viral infections in the myocardium of adults with "idiopathic" left ventricular dysfunction. Circulation. 2005; 111: 887-893. Ref.: http://bit.ly/2Lvf9so

31. Holzmann M, Nicko A, Kühl U, Noutsias M, Poller W, et al. Complication rate of right ventricular endomyocardial biopsy via the femoral approach. Circulation 2008; 118: 1722-1728. Ref.: http://bit.ly/2RPyfL1

32. Escher F, Lassner D, Kühl U, Gross U, Westermann D, et al. Analysis of Endomyocardial Biopsies in suspected Myocarditis - Diagnostic Value on Left versus Right Ventricular Biopsy. Int J Cardiol. 2014; 177: 76-78. Ref.: http://bit.ly/2YoRptM

33. Aretz HT. Myocarditis: the Dallas criteria. Hum. Pathol. 1987; 18: 619-624. Ref.: http://bit.ly/2FJ6wHb

34. Towbin JA, Lowe AM, Colan SD, Sleeper LA, Orav EJ, et al. Incidence, causes, and outcomes of dilated cardiomyopathy in children. JAMA. 2006; 296: 1867-1876. Ref.: http://bit.ly/2FGB8ZF

35. Bowles NE, Ni J, Kearney DL, Pauschinger M, Schultheiss HP, et al. Detection of viruses in myocardial tissues by polymerase chain reaction. Evidence of adenovirus as a common cause of myocarditis in children and adults. J Am Coll Cardiol. 2003; 42: 466-472. Ref.: http://bit.ly/2KRjqHk

36. Pauschinger M, Phan MD, Doerner A, Kuehl U, Schwimmbeck PL, et al. Enteroviral RNA replication in the myocardium of patients with left ventricular dysfunction and clinically suspected myocarditis. Circulation. 1999; 99: 889-895. Ref.: http://bit.ly/325qjKj

37. Kühl U, Rohde M, Lassner D, Gross UM, Escher F, et al. miRNA as activity markers in Parvo B19 associated heart disease. Herz. 2012; 37: 637-643. Ref.: http://bit.ly/2XhbYM9

38. Kuchynka P, Palecek T, Masek M, Cerny V, Lambert L, et al. Current Diagnostic and Therapeutic Aspects of Eosinophilic Myocarditis. Biomed Res Int. 2016; 2016: 2829583. Ref.: http://bit.ly/322bpVq

39. Maleszewski JJ, Orellana VM, Hodge DO, Kuhl U, Schultheiss HP, et al. Long-term risk of recurrence, morbidity and mortality in giant cell myocarditis. Am J Cardiol. 2015; 115: 1733-1738. Ref.: http://bit.ly/2J0altr

40. Larsen BT, Maleszewski JJ, Edwards WD, Cooper LT Jr, Sobonya RE, et al. Atrial giant cell myocarditis: a distinctive clinicopathologic entity. Circulation. 2013; 127: 39-47. Ref.: http://bit.ly/2xpMBIw

41. Lassner D, Kühl U2, Siegismund CS3, Rohde M3, Elezkurtaj S, et al. Improved diagnosis of idiopathic giant cell myocarditis and cardiac sarcoidosis by myocardial gene expressing profil. Eur Heart J. 2014; 35: 2186-2195. Ref.: http://bit.ly/2KOmaoX

42. Grogan M, Redfield MM, Bailey KR, Reeder GS, Gersh BJ, et al. Long-term outcome of patients with biopsy-proved myocarditis: comparison with idiopathic dilated cardiomyopathy. J Am Coll Cardiol. 1995; 26: 80-84. Ref.: http://bit.ly/323vgDq

43. Schultheiss HP, Kühl U. Why is diagnosis of infectious myocarditis such a challenge? Expert Rev Anti Infect Ther. 2011; 9: 1093-1095. Ref.: http://bit.ly/2YuuXzC

44. Kühl U, Lassner D, von Schlippenbach J, Poller W, Schultheiss HP, et al. Interferon-Beta improves survival in enterovirus-associated cardiomyopathy. J Am Coll Cardiol. 2012; 60: 1295-1296. Ref.: http://bit.ly/31ZqIDy

45. Verdonschot J, Hazebroek M, Merken J, Debing Y, Dennert R, et al. Relevance of cardiac parvovirus B19 in myocarditis and dilated cardiomyopathy: review of the literature. Eur J Heart Fail. 2016; 18: 1430-1441. Ref.: http://bit.ly/322hDVi

46. Hjalmarsson C, Liljeqvist JÅ, Lindh M, Karason K, Bollano E, et al. Parvovirus B19 in Endomyocardial Biopsy of Patients With Idiopathic Dilated Cardiomyopathy: Foe or Bystander? J Card Fail. 2019; 25: 60-63. Ref.: http://bit.ly/2Nq3vBP 
47. Verdonschot JAJ, Cooper LT, Heymans SRB. Parvovirus B19 in Dilated Cardiomyopathy: There Is More Than Meets the Eye. J Card Fail. 2019; 25: 64-66. Ref.: http://bit.ly/2YotqLb

48. Kühl U, Lassner D, Pauschinger M, Gross UM, Seeberg B, et al. Prevalence of erythrovirus genotypes in the myocardium of patients with dilated cardiomyopathy. J Med Virol. 2008; 80: 1243-1251. Ref.: http://bit.ly/2YnP7Lu

49. Schmidt-Lucke C, Spillmann F, Bock T, Kühl U, Van Linthout S, e al. Interferon beta modulates endothelial damage in patients with cardiac persistence of human parvovirus b19 infection. J Infect Dis. 2010; 201: 936-945. Ref.: http://bit.ly/2XjAaO6

50. Schmidt-Lucke C, Zobel T, Schrepfer S, Kuhl U, Wang D, et al. Impaired Endothelial Regeneration Through Human Parvovirus B19-Infected Circulating Angiogenic Cells in Patients With Cardiomyopathy. J Infect Dis. 2015; 212: 1070-1081. Ref.: http://bit.ly/2XdkBCK

51. Kuhl U, Lassner D, Dorner A, Rohde M, Escher F, et al. A distinct subgroup of cardiomyopathy patients characterized by transcriptionally active cardiotropic erythrovirus and altered cardiac gene expression. Basic Res Cardiol. 2013; 108: 372. Ref.: http://bit.ly/2XmaQXN

52. Escher F, Kühl U, Gross U, Westermann D, Poller W, et al. Aggravation of left ventricular dysfunction in patients with biopsy-proven cardiac human herpesvirus A and B infection. J Clin Virol. 2015; 63 1-5. Ref.: http://bit.ly/2ZYOZUL

53. Pellett PE, Ablashi DV, Ambros PF, Agut H, Caserta MT, et al. Chromosomally integrated human herpesvirus 6: questions and answers. Rev Med Virol. 2012; 22: 144-155. Ref.: http://bit.ly/2Nozkem

54. Kühl U1, Lassner D, Wallaschek N, Gross UM, Krueger GR, et al. Chromosomally integrated human herpesvirus 6 in heart failure: prevalence and treatment. Eur J Heart Fail. 2015; 17: 9-19. Ref.: http://bit.ly/2xoAyeM

55. Escher F, Kühl U, Lassner D et al. Presence of Perforin in Endomyocardial Biopsies of Patients with Inflammatory Cardiomyopathy Predicts Poor Outcome. Eur J Heart Fail. 2014; 16: 1066-1072. Ref.: http://bit.ly/2XJ6xVH

56. Baldeviano GC, Barin JG, Talor MV, Srinivasan S, Bedja D, et al. Interleukin-17A is dispensable for myocarditis but essential for the progression to dilated cardiomyopathy. Circ Res. 2010; 106: 16461655. Ref.: http://bit.ly/2JkDkqL

57. Wu L, Ong S, Talor MV, Barin JG, Baldeviano GC, et al. Cardiac fibroblasts mediate IL-17A-driven inflammatory dilated cardiomyopathy. J Exp Med. 2014; 211: 1449-1464. Ref.: http://bit.ly/2FHTWaY

58. Myers JM, Cooper LT, Kem DC, Stavrakis S, Kosanke SD, et al. Cardiac myosin-Th17 responses promote heart failure in human myocarditis. JCI Insight. 2016; 1. Ref.: http://bit.ly/325QYqi

59. Rahmati Z, Amirzargar AA, Saadati S, Rahmani F, Mahmoudi MJ, et al. Association of levels of interleukin 17 and T-helper 17 count with symptom severity and etiology of chronic heart failure: a case-control study. Croat Med J. 2018 31; 59: 139-148. Ref.: http://bit.ly/2XkFctq

60. Wu L, Diny NL, Ong S, Barin JG, Hou X, et al. Pathogenic IL-23 signaling is required to initiate GM-CSFdriven autoimmune myocarditis in mice. Eur J Immunol. 2016; 46: 582-592. Ref.: http://bit.ly/2Xkalxr

61. Suthahar N, Meijers WC, Silljé HHW, de Boer RA. From Inflammation to Fibrosis-Molecular and Cellular Mechanisms of Myocardial Tissue Remodelling and Perspectives on Differential Treatment Opportunities. Curr Heart Fail Rep. 2017; 14: 235-250. Ref.: http://bit.ly/2NpphFY

62. Westermann D, Lindner D, Kasner M, Zietsch C, Savvatis K, et al. Cardiac inflammation contributes to changes in the extracellular matrix in patients with heart failure and normal ejection fraction. Circ Heart Fail. 2011; 4: 44-52. Ref.: http://bit.ly/2Lz9y4F

63. Piek A, de Boer RA, Silljé HH. The fibrosis-cell death axis in heart failure. Heart Fail Rev. 2016; 21: 199-211. Ref.: http://bit.ly/2FN1gCu

64. Schultheiss HP, Escher F. The ESC Textbook of Cardiovascular Medicine, Third Edition, 2019. Chapter 32.21: Myocarditis - Treatment of myocarditis.

65. Hershberger RE, Hedges DJ, Morales A. Dilated cardiomyopathy: the complexity of a diverse genetic architecture. Nat Rev Cardiol. 2013; 10: 531-547. Ref.: http://bit.ly/2FJbDY2

66. Heymans S, Hirsch E, Anker SD, Aukrust P, Balligand JL, et al. Inflammation as a therapeutic target in heart failure? A scientific statement from the Translational Research Committee of the Heart Failure Association of the European Society of Cardiology. Eur J Heart Fail. 2009; 11: 119-129. Ref.: http://bit.ly/2RQbarQ

67. Sotiriou E, Heiner S, Jansen T, Brandt M, Schmidt KH, et al. Therapeutic implications of a combined 
diagnostic workup including endomyocardial biopsy in an all-comer population of patients with heart failure: a retrospective analysis. ESC Heart Fail. 2018; 5: 630-641. Ref.: http://bit.ly/2XAjvVO

68. Kühl U, Pauschinger M, Schwimmbeck PL, Seeberg B, Lober C, et al. Interferon-beta treatment eliminates cardiotropic viruses and improves left ventricular function in patients with myocardial persistence of viral genomes and left ventricular dysfunction. Circulation. 2003; 107: 2793-2798. Ref.: http://bit.ly/2FIR3H6

69. Schultheiss HP, Piper C, Sowade O, Waagstein F, Kapp JF, et al. Betaferon in chronic viral cardiomyopathy (BICC) trial: Effects of interferon- $\beta$ treatment in patients with chronic viral cardiomyopathy. Clin Res Cardiol. 2016; 105: 763-773. Ref.:

70. Poller W, Kaya Z, Muche M, Kasner M, Skurk C, et al. High incidence of cardiac dysfunction and response to antiviral treatment in patients with chronic hepatitis $C$ virus infection. Clin Res Cardiol. 2017; 106: 551-556. Ref.: http://bit.ly/2XNmg6p

71. Zobel T, Bock CT, Kühl U, Rohde M, Lassner D, Schultheiss HP, Schmidt-Lucke C. Telbivudine Reduces Parvovirus B19-Induced Apoptosis in Circulating Angiogenic Cells. Viruses. 2019; 11. Ref.: http://bit.ly/300osEJ

72. Cooper LT. The heat is off: immunosuppression for myocarditis revisited. Eur Heart J. 2009; 30 : 1936-1939. Ref.: http://bit.ly/2ZXB7Za

73. Frustaci A, Russo MA, Chimenti C. Randomized study on the efficacy of immunosuppressive therapy in patients with virus-negative inflammatory cardiomyopathy: the TIMIC study. Eur Heart J. 2009; 30 1995-2002. Ref.: http://bit.ly/2KQSQy8

74. Frustaci A, Chimenti C, Calabrese F, Pieroni M, Thiene G, et al. Immunosuppressive therapy for active lymphocytic myocarditis: virological and immunologic profile of responders versus nonresponders. Circulation. 2003; 107: 857-863. Ref.: http://bit.ly/2XgJdzf

75. Escher F, Kühl U, Lassner D, Poller W, Westermann D, et al. Long-term outcome of patients with virusnegative chronic myocarditis or inflammatory cardiomyopathy after immunosuppressive therapy. Clin Res Cardiol. 2016; 105: 1011-1020. Ref.: http://bit.ly/2XDKHmG

76. McNamara DM, Holubkov R, Starling RC, Dec GW, Loh E, et al. Controlled trial of intravenous immune globulin in recent-onset dilated cardiomyopathy. Circulation. 2001; 103: 2254-2259. Ref.: http://bit.ly/2FIRJfC

77. Felix SB, Staudt A, Dörffel WV, Stangl V, Merkel K, et al. Hemodynamic effects of immunoadsorption and subsequent immunoglobulin substitution in dilated cardiomyopathy: three-month results from a randomized study. J Am Coll Cardiol. 2000; 35: 1590-1598. Ref.: http://bit.ly/321ylym

78. Fan Y, Weifeng W, Yuluan Y, Qing K, Yu P, et al. Treatment with a neutralizing anti-murine interleukin-17 antibody after the onset of coxsackievirus b3-induced viral myocarditis reduces myocardium inflammation. Virol J. 2011; 8: 17. Ref.: http://bit.ly/2YxyrkV

79. Adegbala O, Olagoke $\mathrm{O}$, Akintoye E, Adejumo AC, Oluwole A, et al. Predictors, Burden, and the Impact of Arrhythmia on Patients Admitted for Acute Myocarditis. Am J Cardiol. 2019; 123: 139-144. Ref.: http://bit.ly/2ZWMsZB

80. Caforio ALP, Cheng C, Perazzolo Marra M, Tarantini G, Basso C, et al. How to improve therapy in myocarditis: role of cardiovascular magnetic resonance and of endomyocardial biopsy. Eur Heart $\mathrm{J}$ Suppl. 2019; 21(Suppl B): B19-B22. Ref.: http://bit.ly/2YxVDiA

81. Caforio AL, Mahon NJ, Mckenna WJ. Cardiac autoantibodies to myosin and other heart-specific autoantigens in myocarditis and dilated cardiomyopathy. Autoimmunity. 2001; 34: 199-204. Ref.: http://bit.ly/2XeOGBy

82. Kasner M, Aleksandrov A, Escher F, Al-Saadi N, Makowski M, et al. Multimodality imaging approach in the diagnosis of chronic myocarditis with preserved left ventricular ejection fraction (MCpEF): The role of 2D speckle-tracking echocardiography. Int J Cardiol. 2017; 243: 374-378. Ref.: http://bit.ly/2RLy6IE

83. Ponikowski P, Voors AA, Anker SD, Bueno H, Cleland JGF, et al. 2016 ESC Guidelines for the diagnosis and treatment of acute and chronic heart failure: The Task Force for the diagnosis and treatment of acute and chronic heart failure of the European Society of Cardiology (ESC) Developed with the special contribution of the Heart Failure Association (HFA) of the ESC. Eur Heart J. 2016; 37: 21292200. Ref.: http://bit.ly/2J1m4bd

84. Gorbea C, Makar KA, Pauschinger M, Pratt G, Bersola JL, et al. A role for Toll-like receptor 3 variants in host susceptibility to enteroviral myocarditis and dilated cardiomyopathy. J Biol Chem. 2010; 285 23208-23223. Ref.: http://bit.ly/2XfsffM 
85. Zimmermann $\mathrm{O}$, Rodewald C, Radermacher $\mathrm{M}$, Vetter $\mathrm{M}$, Wiehe JM, et al. Interferon beta- $1 \mathrm{~b}$ therapy in chronic viral dilated cardiomyopathy-is there a role for specific therapy? J Card Fail. 2010; 16: 348-356. Ref.: http://bit.ly/2XD8pPH

86. Bachelier K, Biehl S, Schwarz V, Kindermann I, Kandolf R, et al. Parvovirus B19-induced vascular damage in the heart is associated with elevated circulating endothelial microparticles. PLoS One. 2017; 12: e0176311. Ref.: http://bit.ly/2XFMpnt

87. Kühl U, Rohde M, Lassner D, Gross UM, Escher $F$, et al. miRNA as activity markers in Parvo B19 associated heart disease. Herz. 2012; 37: 637-643. Ref.: http://bit.ly/2XhbYM9 